\title{
NUANSA SASTRA ISLAM DALAM PENDIDIKAN ISLAM
}

\author{
M. Abd. Rahman \\ Prodi Pendidikan Agama Islam, Fakultas Agama Islam, Universitas Nahdlatul \\ Ulama Indonesia (UNUSIA) \\ Email: rahman@unusia.ac.id
}

Article Information

http://journal.unusia. ac.id/index.php/moz aic/

DOI:

10.47776/mozaic.v7i

1.167

Informasi Artikel

Naskah diterima: 11

January 2021

Naskah direvisi: 13

Maret 2021 April

2021

Naskah disetujui: 25

April 2021

Naskah dipublish:

29 April 2021

Keywords Islamic

Literature, Islamic

Education, Syair

Tradition

Kata Kunci

Litelatur Islam,

Pendidikan Islam,

Tradisi syair
Abstact

This study aims to find a correlation between islamic literature and islamic education in Indonesia in historical perception. The data are analyzed using descrptive-analysis method by historical approach. The result showed that in islamic litearature there are values of education becau se of the use of literature often in the medium of the dakwah.

\section{PENDAHULUAN}

Sastra merupakan hasil cipta manusia yang menggunakan bahasa (tulisan atau lisan) sebagai medianya, bersifat imajinatif namun walaupu seluruh karya sas tra bersifat imajinatif karya sastra mengandung pesan-pesan yang tersimpan. Dalam sosiologi sastra, karya sastra dipandang sebagai dokumen yang di dalamnya 
menggambarkan refleksi situasi pada masa sastra diciptakan. Atau, karya sastra merupakan manifestasi dari kondisi sosial budaya dan peristiwa sejarah. ${ }^{1}$

Dalam bahasa Arab kata adab أدب sering dipakai sebagai kata padanan dari kata sastra, sementara dalam bahasa Indonesia kata adab berarti kesopanan, kehalusan dan kebaikan budi pekerti atau akhlak. Dalam sejarahnya kata adab selalu mengalami perubahan makna yang disesuaikan dengan masa dimana kata tersebut dipergunakan . Masyarakat Arab Jahiliyah memaknai kata adbun (bukan adab) dengan undangan untuk menyantap makanan. Tradisi semacam ini dianggap sebagai perbuatan yang sangat terpuji dan bentuk moral yang tinggi. Pada masa permulaan Islam, kata $a d a b$ mencakup makna Pendidikan lisan dan Pendidikan budi pekerti, serta menjauhi أَدَبَنِيْ رَبِّي فَأَخْسَنَ تَأُدِيِيْ yang bermakna tuhanku terlah mendidikku, kemudian menjadi baik pendidikanku. sementara pada masa Bani Umayyah, kata adab bermakna pengajaran, maka, pada era ini kata معلم (pengajar) sama maknanya dengan kata مؤدب. Pengertian Pendidikan pada masa ini mencakup perilaku kehidupan yang baik, Pendidikan budi pekerti, dan Pendidikan lisan (etika berbicara) ${ }^{2}$

Pendidikan Islam adalah totalitas kegiatan manusia muslim yang dilakukan secara sungguh-sungguh, sadar, terencana, terstruktur dan berkesinambungan atas dasar iman dan takwa kepada Allah Swt. Dapat ditegaskan bahwa proses Pendidikan itu mencakup aktivitas yang sangat luas, beragam, dan kompleks. Dalam proses Pendidikan itu terkandung pula upaya sadar yang disebut al-ta'lim (pemberian nasihat, pembelajaran), al-ta'dib (disiplin, patuh, dan taat kepada aturan, hukum, sopan santun, tata krama, budi pekerti, akhlak, moral, etika), al-tahdzib (Pendidikan akhlak atau moral yang baik dan besih). ${ }^{3}$

Faktor pertama dalam mengkaji Bahasa dan puisi Arab Jahilliyah dapat dilihat dari pendapat yang mengatakan bahwa Bahasa anugerah Tuhan kepada Nabi Adam As yang menyebabkan adanya hubungan substansial antara Bahasa dan agama. Dengan begitu dapat dikatakan bahwa usia Bahasa Arab sama tuanya dengan Nabi

\footnotetext{
${ }^{1}$ Ahmad Muzakki, Kesusastraan Arab Pengantar Teoridan Terapan. (Yogyakarta: Ar-Ruz Media, 2006). 34

${ }^{2}$ Wildana wargadinanta dan Laily Fitriiani, SastraArab Dan Lintas Budaya.(Malang: UIN Malang Press, 2008). 35.

${ }^{3}$ Prof. Dr. Faisal Ismail, MA. Paradigma Pendidikan Islam, Analisis Historis, Kebijakan dan Keilmuan.(PT remaja rosdakarya:2017). 5.
} 
Adam. Kajian mengenai Bahasa-puisi menjadi sarana untuk mengenali agama dan memahami Al-Qur'an. ${ }^{4}$ Menurut perspektif ini Bahasa Arab bersifat eternal ketuhanan, dan siapa saja yang meriwayatkannya harus memperlakukannya seperti perlakuannya dalam meriwayatkan hadis. Masih menurut pandangan ini, puisi jahiliyah dikodifikasi dan bahasanya dianggap sebagai kriteria bagi orisinalitas Bahasa. ${ }^{5}$ Pengetahuan mengenai Bahasa dan puisi Arab Jahiliyah menjadi prasyarat pertama dalam mengetahui kemukjizatan al-Qur'an. Penguasaan terhadap keduanya menjadi tolok ukur dalam merasakan dzauq kekmukjizatan al-Qur'an yang pada akhirnya orang Arab sendiri menyadari bahwa mereka tidak mampu membuat yang sama dengan al-Qur'an pada gilirannya mereka bisa mengimani bahwa al-Qur'an benar-benar merupakan wahyu. ${ }^{6}$ Seperti itulah, orang Arab lebih melihat al-Qur'an pada masa awal Islam dari sisi bahasanya daripada melihatnya dari sisi muatan keagamaannya. Bahasa menjadi sebab mengapa ia menolak atau menerima al-Qur'an.

\footnotetext{
${ }^{4}$ Tafsir sastra terhadap kitab Al-Qur'an merupakan kewajiban pertama yang harus diu payakan oleh siapa saja yang memiliki kaitan kebahasa sastraan dengan bahasa Arab, apakahorang Arab ata upun bukan. Seputar al-Quran yang berkaitan dengan la tar belakang materil da n spiritual tempat di mana AlQur'an muncul, diwahyukan dalam rentang waktu, dikodifikasikan, ditulis, dib a ca, diha falkan, dan berbica ra untuk pertama kalinya kepada masyarkat di lingkungan tersebut. Kepada merekalah AlQur'an mengerahkan misinya agar mereka bangkit untuk menunaikannya dan m enyampaikannya kepa da bangsa-bangsa didunia. Maka, semangat Al-Qur'an a dalah kearaban, corak wa rnanya Arab, style-nya Arab , sebagai ba caan Arab yang lurus. Di sa mping itu, harus dipertimbangkan pula semua yang berkaitan dengan latar belakang spiritual dengan segala maknanya dari kata spiritual tersebut yang sangat luas, masa la lu zaman dahulu kala, sejarah mereka, sistem keluarga, atau kabilah, pemerintahan dan berbagaisenimeskipun beragam coraknya. Jika kajian sastra beru saha keras mengenal ba hasa Arab dan kearaban secara lebih jauh, lebih dalamdan lebih cermat, dengan harapan agar kajian ini da pat mengkaji sa stra bahasa Arab secara benar, hal itu karena Al-Qur'an ini merupakan puncak tertinggi dan utama sastra ini, merupakan jantungnya y ang berdeny ut. Amin al-Khulli dan Nasr H \{a >mid Abu>Zayd, Metode Tafsir Sastra, terj. Khoiron Nahdliyin (Yogyakarta: Adab Press, 2004), 63-68.

${ }^{5}$ Masa kodifikasi disebut dengan 'as $\}$ r al-tadwi $>n$ yaitu masa dimana berlangsung proyek konstruksi budaya secara masif dalam pengalaman sejarah peradaban Islam, antara pertengahan abad ke- $2 \mathrm{H}$ d an pertengahan abadke-3 H. Sela njutnya, peradaban inimem bentuk sebuah kerangka rujukan bagi pemikiran Arabdengan segenap disiplin keilmuannya yang beragam. 'as $\} \mathrm{r}$ al-tadwi $>n$ bukanlah seka dar proses pembukuan dan pembakuan disiplin-disiplin keilmuan, yang sebenarnya sudah muncul sebelum pada masa sebelumnya. Tapi kita harus memahaminya sebagai sebuah rekonstruksi kebudayaan secara menyeluruh, dengan segenap yang dikandung proses tersebut, baik yang berupa elimina si, da n suplementasi, dominasi, pembungkaman, manipulasi, dan penafsiran, yang kesemuanya itu dipenga ruhi oleh faktor-faktor ideologis danfaktor-faktor sosio-kultural yang beragam. Di m a sa inilah bahasa Arab dibakukan, beberapa disiplin keilmuan Islam, seperti hadis, fiqh, dan tafsir, dibentuk dan dirumuskan, termasuk penerjemahan tra disi pemikiran filsafat Yu nani-Hellenis me ke da lam bahasa Arab. Keseluruhan proses tersebut berlangsung tumpang tindih, berinteraksi antara sa tu dengan lainnya. Ini berdampak pada hubungan a ntara bahasa dan pemikiran dalam kebudayaan Is lam Arab. Muh \}ammad 'A $<$ bid al-Ja>biri>, Post Tradisionalisme Islam, terj. Ahmad Baso (Yogy akarta: LKIS, 2000), 60-61.

${ }^{6} \mathrm{Adu}>\mathrm{ni}>\mathrm{s}$, al-Tha $>$ bit wa al-Mutah\}awwil: Bahlthfi $>$ al-Ittiba> 'wa al-Ibda> ' 'inda al- 'Arab. Vol. II, 151.6
} 
Dalam penelitian ini penulis bermaksud mempertemukan antara sastra dan Pendidikan islam melalui hubungan sastra dengan al-Qur'an, sastra dianggap sebagai budaya arab yang mengakar bahkan sebelum islam dikenal dan al-Qur'an sebagai sumber dari semua ajaran islam termasuk Pendidikan.

Sastra (sya'ir, cerpen, novel dan semua produk sastra) mempunyai hubungan yang erat dengan pendidikan, katerkaitan ini bukan hanya disebabkan karena sastra mempunyai peranan yang penting dalam pendidikan, melainkan karena keduan ya pada manusia. Sastra dan pendidikan sama-sama hadir dari dan untuk manusia. Sastra dibaca dalam kerangka pembudayaan manusia, pendidikan juga dikelola dalam kerangka yang sama. Kalau sastra mengeksplorasi dan mangaktualisasi sekian banyak aspek kehidupan, pendidikan juga berbuat hal yang serupa. Karena itu, tidak diragukan lagi bahwa sastra berkaitan erat dengan pendidikan. ${ }^{7}$

\section{METODE PENELITIAN}

Pengolahan data dalam penelitian ini menggunakan metode deskriptif-analitis dengan pendekatan sejarah. ${ }^{8}$ Penelitian ini berupay a mendeskripsikan, menganalisa dan menginterpretasikan data-data yang berkaitan dengan sastra islam dan pendidikan islam.

\section{DIALEKTIKA AL-QUR'AN, SASTRA DAN KULTUR BAHASA ARAB}

Dalam berinteraksi dengan al-Qur'an, Amin Al-khulli memulai asumsinya melalui pendekatan dan sudut pandang sastra. Menurutnya, adalah sebuah fakta bahwa al-Qur'an merupakan fakta bahasa dan sastra. Namun fakta ini bukan fakta yang mati, tetapi dinamis karena memiliki pengaruh yang jelas terhadap mereka yang menjadi sasaran pertama dari ujaran-ujarannya. Al-Qur'an di sini dilihat sebagai apa adanya dalam kaitannya dengan masyarakat pertama kali menerimanya. Ia muncul dalam bingkai dialektika antara wahyu dengan realitas masyarakat pada saat itu.

\footnotetext{
${ }^{7}$ Tirto Suwondo, Sastra dan Pendidikan, Majalah Candra (Disdikpora DIY, Edisi 3, Thn, XLVII, 2017) 7$.

${ }^{8}$ Kuntowijoyo membatasi penelitian tentang sejarah pemikiran dengan tiga tugas yang harus dila kukan oleh peneliti, yaitu 1. Membicarakan pemikiran-pemikiran besar yang berpen garuh pada kejadian sejarah; 2. Membicarakan kontes sejarahnya; 3 . Pengaruh pemikiran pada masyarakat bawah. Kuntowijoyo, Metodologi Sejarah. (Yogyakarta:Tiara Wacana, 2003), 191.
} 
Seperti itulah Amin Al-khulli melihat al-Qur'an sebagai bagian dari fakta-fakta so sio kultural. ${ }^{9}$

Al-Qur'an sebagai kitab suci dan sumber hukum agama Islam sampai kepada kita dengan menggunakan Bahasa Arab. Al-Qur'an sebagai teks suci bisa dikatakan sebagai teks yang sangat fenominal hal ini dikarenakan di satu sisi al-Qur'an merupakan kalam ilahi dan di sisi lain al-Qur'an tidak bisa dipisahkan dari situasi kultural-historis zamannya, dalam arti al-Qur'an mnggunakan bahasa arab sekaligu s dengan system bahasa para penuturnya, namun pada kenyatannya tidak ada satupun dari masyarakt Arab bahkan yang paling ahli dalam bahasnya yang dapat menandin gi bahasaya yang digunakan al-Qur'an dari segi isi, gramatikal maupun stilistika. Karena keunikan dan kekhasan al-Qur'an itulah beberapa ilmuwan muslim seperti ibn Hazm $(456 \mathrm{H})$ dan Adonis berpendapat bahwa al-Qur'an adalah bahasa al-Qur'an, kita tidak bisa memberikan nama terhadap bahasa kitab al-Qur'an. ${ }^{10}$

Sumber-sumber hukum Islam, Al-Qur'an dan hadis merupakan pernyataan berbahasa arab. Islam memiliki karakter arab hal ini merupakan bentuk kon sekuensi dari bentuk historisnya. Hal ini tidak berarti memberikan kesan interpretasi Arabosentris mengenai Islam, karena merupakan definisi teoogis tentang Islam, karena merupakan bagian dari definisi teologis tentang Islam dimana kitab sucinya, al-Qur'an dan ritual-ritualnya (termasuk shalat) hanya dapat dilakukan atau dipraktekkan dalam bahasa Arab. Dengan demikian bahasa Arab merupakan medium artikulasi dalam sisitem sosiokultural Islam. Bahkan pada masa pra Islam bahasa Arab sudah merupakan bahasa tertulis yang sophisticated, diantara prestasi budaya dalam bahasa Arab adalah syi'ir mu'allaqat yang sangat bagus. Namun demikian, oleh kaum muslim Al-Qur'an dipandang sebagai kulminasi perkembangan bahasa Arab, se jak saat itu bahasa Arab memperoleh status bahasa Al-Qur'an dan pada umumnya didefinisikan sebagai bahasa yang suci. Bahasa Arab sebagaimana bahasa yang lain, merupakan subjek bagi faktor-faktor perubahan sosial, dan oleh karena itu berubah bersama perubahan budaya. ${ }^{11}$

\footnotetext{
${ }^{9}$ Khoiron Nahdiyyin, Metode Taf sir Sastra, (Yogyakarta: Adab Press, 2004), vi

${ }^{10} \mathrm{Adu}>\mathrm{ni}>\mathrm{s}$, al-Nas\}s\}\} al-Qur'a $>n i>$ wa A<fa $>$ qal-Kita $>$ bah (Beirut:al-Da>ral-Adab), 19.

${ }^{11}$ Bassam Tibi, Islam, Kebudayaan dan Perubahan Sosial, terj. MisbahZulfa Ellizabet, Zainul Aba s (Yogyakarta: PT Tiara Wacana Yogya, 1999), 94-95.
} 
Dialektika antara Al-Qur'an dengan basis kultur bahasa Arab dapat dilihat dari beberapa hal diantaranya, dari proses diturunkannya Al-Qur'an kepada Nabi Muhammad SAW yang lazim disebut dengan wahyu. Sejak awal diturunkannya, AlQur'an telah melibatkan dirinya ke dalam sebuah ruang komunikasi. Komunikasi antara Tuhan, malaikat, dan hamba pilihan, yakni Muhammad SAW, sebelum disampaikan kepada umat manusia. Setidaknya, hal seperti ini dapat ditemukan dalam konsep wahyu yang telah menjadi konsep sentral dalam memahami Al-Qur'an itu sendiri. ${ }^{12}$

Dalam beberapa literatur akan ditemukan beragam makna tentang wahyu, ${ }^{13}$ namun pada dasarnya konsep wahyu dalam Al-Qur'an adalah pemberian informasi secara rahasia dan cepat. Wahyu tidak lain merupakan proses komunikasi yang mengandung pesan dan bersifat rahasia. ${ }^{14}$ Konsep wahyu seperti itu memiliki keterkaitan erat dengan basis kultur bahasa yang berkembang di tengah masyarakat Arab. Menurut Nasr Hamid Abu Zayd, bahwa fenomena wahyu tidak dapat dilepaskan dari realitas setempat. ${ }^{15}$ Masyarakat Arab sebelum Islam dating telah mengenal model-model komunikasi antara manusia dengan alam-alam lain seperti malaikat dan setan atau jin, ditengah masyarakat Arab model komunikasi seperti ini tampak terllihat jelas dalam sastra (puisi) dan praktik perdukunan atau yang lebih dikenal dengan istilah saj' al-kuhhan. ${ }^{16}$

Bagi orang Arab, jin bisa berbicara kepada sastrawan (penyair) dan membisikkan puisi kepadanya. Ramalan yang ia sampaikan yang berbentuk ungkapan sastrawi itu bersumber dari jin oleh karena itu, bangsa Arab yang hidup pada saat AlQur'an diturunkan, tidak mengingkari fenomena wahyu. Mereka membenarkan adanya malaikat yang turun membawa kalam kepada manusia. Pengingkaran mereka hanya ditujukan pada isi wahyu. Maka tak heran, jika mereka mengkategorikan Al-

\footnotetext{
${ }^{12}$ M. FaisolFatawi, Tafsir SosiolinguistikMemahami Huruf Muqa >t\}a'ah dalam Al-Qur'an (Malang: UIN Malang Press, 2009), 84.

${ }^{13}$ Wahyu menurut pengertian kebahasaan, adalah isyarat yang cepat. Se dan gkan m en urut istila h ba nyak ulama, wa hyu a dalah informasi Allah menyangkut a gama atau semacamnya yang disampaik an kepada nabi-Nya. M. quraish Shihab, Membumikan Al-Qur'an Memfungsikan Wahyu dalam Kehidupan Jilid2 (Ciputat:Lentera Hati, 2011), 522.

${ }^{14}$ M. FaisolFa tawi, Tafsir SosiolinguistikMemahami Huruf Muqa >t\}a'ah dalam Al-Qur'an, 85.

$\left.{ }^{15} \mathrm{Nas}\right\} \mathrm{rHa}>$ mid Abu> Zayd, Tekstualitas al-Qur'a $>$ n Kritik Terhadap UlumulQur'a $>$ n, terj. Khoiron Nahdliyyin (Yogyakarta, LKIS, 2002), 33.

${ }^{16}$ M. FaisolFatawi, Tafsir SosiolinguistikMemahami Huruf Muqa >t\}a'ah dalam Al-Qur'an, 88.
} 
Qur'an sebagai jenis tradisi kebahasaan yang sebelumnya sudah mapan, seperti ceritacerita masa lalu (asatir al-awwalin), puisi (syi'r) dan ucapan seorang dukun. ${ }^{17}$

Komunikasi dalam konteks wahyu dengan komunikasi dalam konteks saj' alkuhhan tentu memiliki perbedaan yakni pada tingkat situasi komunikasi. Komunik asi antara manusia dengan makhluk lain yang terkait dalam tingkat eksistensi y an berbeda, Allah dan malaikat dalam konteks Nabi, dan setan dalam konteks jin. Dalalam konteks pewahyuan Al-Qur'an, Allah secara langsung atau malaikat menyampaikan pesan kepada Nabi. Setelah pesan yang disampaikan itu diterima dan dipahami, maka Nabi pun menyampaikan kepada manusia. Komunikasi Nabi didasarkan pada semacam fitrah dan watak yang diciptakan dan ditetapkan oleh Tuhan. Sementara, tukang ramal membutuhkan peralatan dan sarana bantu dalam melepaskan diri dari hambata-hambatan alam materi, dan untuk berkomunikasi dengan dunia lain. ${ }^{18}$

Hubungan Al-Qur'an dengan puisi, pada satu sisi didasarkan pada aspek kesamaan, pada sisi lain didasarkan pada aspek perbedaan, hubungan tersebut bersifat dialektis, berangkat dari konsepsi-konsepsi dasr yang ada dalam kebudayaan, jika AlQur'an menolak dirinya disebut puisi, dan Muhammad SAW disebut penyair, dan penolakan ini memunculkan pendapat puisi dilarang atau paling tidak dibenci (makruh), kesimpulan semacam ini didasarkan pada satu aspek dari hubungan qur' an dan puisi, sementara aspek lain diabaikan. Teks berusaha menolak sebutan puisi bagi dirinya karena alasan-alasan yang berkaitan dengan konsep bangsa Arab mengenai

\footnotetext{
${ }^{17}$ Ka ta asa>t $\} i>r$ (أساطير) ,dongeng a tau mitos`a dalah legenda a tau cerita-cerita lama. Masyarakat Arab memahaminya dalamarti a nekaberita atau kisah yang menja di bahan pembicaraan santai un tuk menghabiskan waktu, baik isinya benar dan sesuai dengan kenyataan maupun tidak. Dengan demikian, boleh jadi yang mereka maksud dengan ucapan itu adalah bahwa Al-Qur'an tidak lain kecuali kebohongan atau bahwa ia tidak wajar bersumber dari Allah karena isinya santai, tidak sesuai d en gan keagungan Allah. Bisa jadijuga mereka menduga Al-Qur'an a dalah kutipan dari legenda dan kisah la ma y ang beredardi Persia, seperti kisah-kisah yang tercantum dalam buku Kalilah wa Dimnah '. M. Qura ish Shihab, Tafsiral-Misbah Pesan, Kesan, dan Keserasian Al-Qur'an (Ciputat: Lentera Hati, 2011), 21.

${ }^{18}$ Dalam Q. S. al-Shu>'ara>(42): 51, hanya tiga cara yang ditempuh Tuhan un tuk menyampaikan informasi-Nya kepada manusia: a. mimpi/ilham, b. berbicara secara langsung tanpa melihat-Nya, dan c. mengutus malaikat untuk menyampaikan pesan-Nya. Informasi yang diterima se orang $\mathrm{n}$ abi melalui ma likat, bisa jadi melalui malaikat Jibril, Mika il, atau malaikat yang lain, dan dalam konteks ini Na bi saw. Menerimanya dengan salah sa tu dari dua cara. Pertama, dengan mengangkat Na bi ke dimensi ma laikat. Kedua, adalah dengan menurunkan malaikat ke dimensi manusiawi, da nila terjadi, maka siapa yang disekitarnya dapat melihat malaikat it u dala m bentuk manusia. M. Qura ish Shihab, Membumikan Alquran Memfungsikan Wahyu dalam Kehidupan Jilid 2 (Ciputat:Lentera Hati, 2011), 523-524.
} 
esensi puisi dilihat dari sumber dan fungsinya. Teks juga menolak Muhammad disebut penyair sebab fungsi penyair dalam masyarakat tersebut berbeda dari fungsi yang diberikan teks terhadap Muhammad SAW. Penyair menjadi corong kabilah, sedangkan Muhammad SAW adalah penyampai misi (risalah). Puisi merupakan teks yang menyuarakan kepentingan kelompok dalam menghujat mu suh-mu suhnya dan membantu sekutu-sekutunya, atau di dalam memuji para tokoh dan pemimpinnya. Sementara Qur'an adalah teks yang bertujuan merekonstruksi realitas dan mentransformasikannya ke arah yang lebih baik. Dari sinilah muncul penegasan bahwa Muhammad bukan seorang penyair, dukun ata penyihir, dan bahwa Qur'an bukan puisi. ${ }^{19}$

Bahasa merupakan satu elemen yang tak terpisahkan dari segala aspek kehidupan manusia. Sastra sebagai satu produk dari budaya yang menggunakan bahasa sebagai medianya, merupakan salah satu bentuk dari ekspresi bahasa. Sastra degan segala bentuknya puisi, pantun, prosa dan lainnya merupakan satu bentuk komunikasi antara sastrawan dan para pembacanya. Komunikasi tersebut berbeda dengan komunikasi sehari-hari, hal ini dikarenakan bahasa yang digunakan dalam sastra penuh dengan bahasa metafora bahkan terdapat juga unsur imajinasi.

Dalam sejarah kesusastraan, tujuan dari adanya karya sastra tidak hanya sebagai ekspresi dari para sastrawan melainkan lebih dari hal tersebut, sastrawan mengekpresikan hal-hal yang dialaminya seputar fenomena kehidupan, peristiwa tersebut bisa menyangkut kejadian yang dialami oleh sastrawan itu sendiri (eksternal) bisa juga dari perasaan yang bergejolah dalam jiwa sastrawan. Perasaan tersebut dapat dipengaruhi oleh faktor alam, keadaan kehidupan, perkembangan ideologi, dan beraneka ragam fenomena lain yang terjadi di tengah masyarakat. ${ }^{20}$

\section{ANTARA SASTRA ARAB, SASTRA ISLAM DAN PENDIDIKAN ISLAM: SEBUAH TINJAUAN HISTORIS}

Pada dasarnya, karya sastra tidak berbeda dengan karya sejarah, filsafat, atau sosiologi. Kesemuanya mengangkat bahan yang sama, masalah manusia dan kemanusiaan. Yang membedakannya adalah bagaimana bahan yang sama itu diolah ,

\footnotetext{
${ }^{19} \mathrm{Na}$ sr Ha $>$ mid Abu > Zayd, Tekstualitas Alquran Kritik Terha dap Ulumul Qur'a $>$ n, terj. Kho iron Nahdliyyin(Yogy akarta, LKIS, 2002), 172.

${ }^{20}$ Terry Eagleton, Marxisme and Literary Criticism, terj.Zaim Rafiqi (Depok: Desantara, 2002), 31.
} 
disajikan dan diberi penekanan lewat sudut pandang masing-masing. Sejarah, misalnya, mencoba merekonstruksi peristiwa manusia dan kemanusiaan yang terjadi pada masa lalu. Filsafat mencoba mengangkat hakikat keberadaan manusia lewat uraian-uraian rasional, logis, dan sistematik. Adapun sosiologi, mencoba mengangk at keberadan individu dalam kaintannya dengan individu lain dan lingkungan masyarakat dan kebudayaannya. ${ }^{21}$

Sedangkan karya sastra dapat memanfaatkan fakta historis, pemikiran filosofis, atau fakta sosiologis. Bahkan karya sastra juga dapat menggabungkan ketiganya sekaligus. Secara hakiki, yang membedakan karya sastra dengan karya nonsastra adalah dominasi imajinasi. Dalam karya sastra, dominasi imajina si sangat penting. Oleh karena itu, dalam karya sastra semua fakta apapun, cenderung diperlakukan sebagai fiksi. Fakta dalam karya sastra adalah fiksi. Itu pula sebabnya, penilaian terhadap karya sastra tidak berkaitan dengan masalah benar-salah, tetapi berkaitan dengan kesanggupannya menyajikan keindahan estetik. Dengan begitu, fakta yang kemudian menjadi fiksi itu, semata-mata dimaksudkan, agar lahir keindahan estetik. Dalam kaitan itulah, karya sastra dapat juga dilihat sebagai fakta struktural artistik, fakta sosial-komunikasional, dan fakta intertekstual. ${ }^{22}$

\footnotetext{
${ }^{21}$ Maman S. Mahayana, Sembilan Jawabah Sastra Indonesia Sebuah Orientasi Kritik (Ja karta: Bening Publishing, 2005), 40.

${ }^{22}$ Sebagaifa kta struktural-a rtistik, karya sastra dipandang sebagai sebuah struktural yang dibangun atas sejumlah unsur yang bersif atfungsional. Kaitan fungsi seju mlah un sur itu, jika memperlih atkan kepa duan dan koherensi, a kan melahirk an keindahan estetik. Dalam hal ini, keberhasila nnya sa ngat ditentukan oleh kepiawaian pengarang dalammemanfaatkan dan mengolah fak ta menja di fiksi dan membalurinya dengan imajinasi. Ja di, fa kta yang diperoleh lewat penga laman la ngsung a tau tidak langsung itu, tidaklah ditampilakan sebagai fa kta an sich, melainkan sebagai “fakta” yang direk a ya sa. Hasilnya adalah sebuah dunia imajinatif yang di da lamnya segala peristiwa serba mungkin terjadi. Seba gai fak ta sosial-komunikasional, karya sa stra la hir da ri sosok seorang sa strawan yang tidak $d$ apat melepaskan diri dari keberadaanya sebagai anggota masyarakat. Ka rya sa stra dalamhal ini, merupakan tanggapan evaluatif sa strawan atas kondisi so sio-kultural masyarakatnya. Anggapan bahwa karya sastra adalah "cermin masyarakat" sesungguhnya berada di da lam konteks ini. Bagi sa strawan, karya sa stra la lu dija dikan sebagai a latutuk melakukan komunikasitidak la ngsung dengan ma syarakatnya. Jika kemudian terjadi miskomunikasi a tau pemahaman yang berbeda dengan pesan sa strawan, hal itu tidaklah menjadi persoalan. Yang penting bagi sastrawan adalah bahwa ia telah berkarya dan menyampaikan sesuatu lewat karyanya. Soal pemahaman masyarakat pembaca, itu sudah bukan urusan sa strawan lagi. Sedangkan k arya sa stra sebagai fakta intertekstualitas, didasarkan pda anggapan bahwa karya astra sebagai sebuah teks, didalamnya mengadirkan pula teks-teks yang la in, baik yang $\mathrm{m}$ unc ul sebelumnya, maupun yang muncul pada zamannya. Atau, paling tidak, ia mempunyai $k$ ait an denga $n$ teks-teks la in y ang sebelumnya telah ada. Teks y ang la in itu mungkin saja hanya sebatas mengilh a mi, mempengaruhi, mengelolahnya kembali, mempebarui a tau memberontakinya. Dengan kata la in, karya sastra hadir dalam ketegangan antara konvesnsi da n inovasi y ang memungkin kan kehidu pan karya sastra terus berkembang. Maman S. Mahayana, Sembilan Jawabah Sastra Indonesia Sebuah Orientasi Kritik (Jakarta: Bening Publishing, 2005), 40-41.
} 
Dalam karya sastra, antara pengarang dan pembaca menempati posisi yang sama-sama penting. Pengarang sebagai pengahasil karya sastra, sedangkan pem baca berperan sebagai penikmat, pengapresiasi bahkan memaknai karya sastra. dengan kehadiran pembaca inilah karya sastra memainkan peranan sosialnya. Pembaca dapat menemukan dua fungsi dari pembacaannya terhadap karya sastra yaitu fungsi hiburan dan fungsi pelajaran. ${ }^{23}$

Sebagai fungsi pelajaran inilah peranan karya sastra menjadi penting dalam dunia Pendidikan, karya sastra mampu memberikan wawasan realitas sosial, bu da ya, politik karena karya sastra dibangun dari realitas sosial yang dialami oleh pengarang. ${ }^{24}$

Sastra Arab mempunyai sejarah yang Panjang, masyarakat Arab pra-Islam (jahiliyah) sangat dikenal dengan masyarakat yang pandai dalam menggunakan bahasa. Al-Qur'an menggambarkan masyarakat Jahiliyah dengan أَلَُّ الْخِصَّامِ “orang yang sangat kukuh dalam perdebatan” (QS. Al-baqarah 204) dalam surat al-ahzab

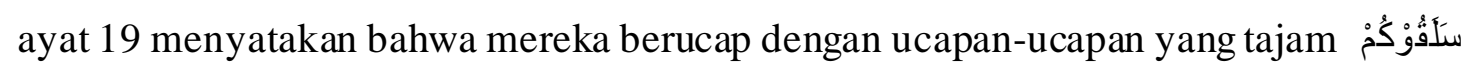
بأَلْسِنَة حِدَادٍ , kiranya hal ini cukup membuktikan bahwa masyarakat jahiliyah merupakan masyarakat yang pandai berdalih dan mahir dalam menyusun kata. ${ }^{25}$

Masyarakat arab memiliki perhatian yang sangat tinggi terhadap Bahasa, bahkan sebelum islam dikenal di dunia Arab. Bagi mereka Bahasa tidak hanya sebagai sarana komunikasi, melainkan juga sebagai sarana untuk meningkatkan pamor dan kemuliaan diantara Bahasa suku-suku lainnya. Bangsa arab juga dikenal dengan masyarakat yang paling ahli dalam penggunaan Bahasa sesuai dengan sense dan warisan Bahasa yang fasih, sesuai dengan yang mereka terima dari para nenek moyang mereka. ${ }^{26}$

Pada awalnya memang sastra arab jahiliyah didominasi dengan tema-tema sya'ir yang membicarakan sifat-sifat yang berkaitan dengan keberanian, kekuatan, tema tentang kebanggan atas kesukuannya, tema pujian akan kecantikan wanita, tema

\footnotetext{
${ }^{23}$ Maman S. Mahayana, Sembilan Jawabah Sastra Indonesia Sebuah Orientasi Kritik (Jakarta: Bening Publishing, 2005), 57-58.

${ }^{24}$ Nyoman Kutha Ratna, Sastra dan Cultural Studies Representasi Fiksi da n Fakta (Yogyakarta: Pustaka Pelajar, 2010), 370.

${ }^{25}$ M. Qura ish Shihab, Pengetahuan masyarakat arabjahiliyah dalam membaca sirahnabi Muhammad SAW dalam sorotan al-Qur'an dan hadits-hadits shahih. (Jakarta: Lentera Hati. 2011). 78

${ }^{26}$ M. Faisol, "Pengaruh Pemikiran Ibnu Madha' Tentang Ushul Al-Nahwi Al-'Arabi Dalam Memahami Teks Kea gamaan," Jurnal Lingua.www.jurnal.com.
} 
tentang kesedihan. Pada era ini juga banyak bermuculan penyair-penyair yang banyak dikenal diantaranya adalah Umru'ul al-Qais, Zuhair ibn Abi Sulma, An-Nabighah Adz-Dzubyani. ${ }^{27}$

Pada masa awal Islam al-Qur'an lebih dilihat dari sisi bahasanya daripada melihatnya dari sisi muatan keagamaannya. Hal inilah yang menjadi salah satu sebab tema-tema sastra Arab sering digunakan sebagai media dakwah. Di Indonesia, pengaruh sastra Arab sangat kental dan berubah menjadi genre tersediri yaitu sastra Islam, banyak ulama-ulama Nusantara yang juga dikenal sebagai seorang sastrawan, sebut saja bagaimana Hamzah Fansuri ${ }^{28}$ menjadi pelopor atas lahirnya Sastra Sufi Melayu. Karya-karya Hamzah Fansuri menjadi pertanda lahirnya era puisi Melayu klasik. ${ }^{29}$

Dalam dunia Pendidikan pesantren, qosidah burdah dari imam al-Bushiri sangat dikenal. Burdah adalah gubahan sya'ir-sya'ir madah (pujian) kepada Nabi Muhammad SAW. Bagai sebuah magnet, bila Burdah dilantunkan secara in dividual atau dalam suatu perhelatan, segera akan menyihir para pendengar, suasana bertambah khidmat dan para pendengarpun ikut larut dalam puisi-puisi indah alBushiri.

Dalam genre cerita pendek, ada karya sastra yang begitu sangat dikenal, Robohnya Surau Kami karangan dari A.A. Navis. Dalam cerpen tersebut A.A. Navis memberikan kritik kepada masyarakat yang taat beragama namun mereka lu pa akan kewajiban sosialnya dan lalai akan tugasnya bermasyarakat dan bernegara. Berikut petikan dari cerpen Robohnya Surau Kami yang menggambarkan kalau manusia diciptakan juga dengan potensi sosial bukan hanya potensi ilahiah.

...Kenapa engkau biarkan dirimu melarat, hingga anak cucumu teraniaya semua. Sedang harta bendamu kaubiarkan orang lain mengambilnya untuk anak сиси mereka. Dan engkau lebih suka berkelahi antara kamu sendiri, saling menipu, saling memeras. Aku beri kau negeri yang kaya raya, tapi kau malas.

\footnotetext{
${ }^{27}$ Ahmadal-Iskandari dan Mus $\{\mathrm{t}\}$ ofa 'Ana $>$ ni. Al-Wasi $\left.>t\right\}$ fi $>$ al-Adabal- 'Arabi wa Tarikhihi. (Kairo: Dar al-Ma'arif, 1978). 70

${ }^{28}$ Perkembangan agama isla m di Indonesia tidak bisa dipisahkan dariempat tokoh yang hidup pada abad ke-16 dan ke 17. Merekaa dalah Hamzah fansuri, Syams al-Din a 1-Su matrani, Nur a 1-Din a 1Raniri, dan 'Abdal-Ra'ufa l-Sinkili. Mastuki dan M. Ishom ElSaha (ed). Intelektual Pesantren, Potret Tokoh dan Cakrawala Pemikiran di Era pertumbuhan Pesantren, (Jakarta: Diva Pustaka, 2003). 35.

${ }^{29}$ V.I. Bra ginsky. Yang Indah, Berfaedah Dan Kamal, Sejarah Sastra Melayu dalam Abad 7 - 19. terj . Hersri Setiawan (Jakarta:INIS, 1998), 449.
} 
Kau lebih suka beribadat saja, karena beribadat tidak mengeluarkan peluh, tidak membanting tulang. Sedang aku menyuruh engkaku semuanya beramal kalau engkau miskin. Engkau kira aku ini suka pujian, mabuk disembah saja, hingga kerjamu lain tidak memuji-muji dan menyembahku saja. Tidak. Kamu semua mesti masukneraka... ${ }^{30}$

Petikan cerpen di atas merupakan dialog antara tuhan dan manusia yang tinggal di bumi Indonesia yang juga digambarkan dengan negeri yang kaya raya namu banyak rakyatnya yang hidup melarat. Dalam petikan tersebut bisa diambil pelajaran bahwa bentuk ibadah bukan hanya ibadah sholat, dzikir dan sem acamnya. Namun, mencari karunia allah, menafkahi keluarga, mengelola bumi dengan sebaik mungkin untuk kemaslahatan bersama juga merupakan tugas manusia sebagai makhluk so sial, dan ini juga selaras dengan ayat al-Qur'an surat Yunus ayat 67

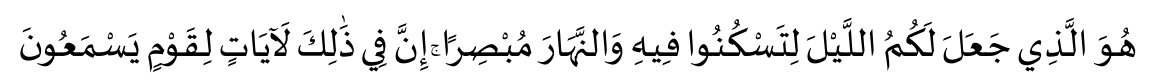

"Dialah yang menjadikan malam bagi kamu supaya kamu beristirahat padanya dan (menjadikan) siang terang benderang (supaya kamu mencari karunia Allah). Sesung guhnya pada yang demikian itu terdapat tanda-tanda (kekuasaan Allah) bag $i$ orang-orang yang mendengar."

\section{KESIMPULAN}

Karya sastra sebenarnya bukanlah sebuah karya yang kosong tanpa pesan, karya sastra juga bisa menjadi media dalam menyampaikan nilai-nilai pendidikan. Dalam sejarahnya banyak para ulama selain dia a'lim (pintar) dalamilmu keagamaan juga pintar dalam hal kesusatraan. Hal ini disebabkan karena karya sastra mempunyai gaya bahasa yang khas, bahasa yang tidak kaku dan monoton seperti karya-karya ilmiah.

Walaupun karya sastra mempunyai unsur imajinasi didalamnya hal ini tidak lantas menjadikan karya sastra menjadi karya yang kering tanpa nilai pendidikan, justru karena unsur imajinasi tersebut menjadikan karya sastra akan sangat dinikmati oleh pembacanya. Nilai-nilai yang terkandung dalam karya sastra merupakan hasil pengalaman dari pengarangnya yang berinteraksi dengan dunia realitas sosialnya

\footnotetext{
${ }^{30}$ A.A. Na vis. Robohnya Surau Kami. (Jakarta: PT Gramedia Pustaka Utama. 2004), 11.
} 
sehingga menjadikan karya sastra kaya dengan nilai-nilai kebudayaan atau pendidikan, karena pastinya setiap pengarang akan berbeda pengalaman interaksinya.

\section{DAFTAR PUSTAKA}

Abu> Zayd, Nas\}r Ha>mid Tekstualitas al-Qur'a>n Kritik Terhadap Ulumul Qur'a>n, terj. Khoiron Nahdliyyin. Yogyakarta, LKIS, 2002.

Adu>ni>s. al-Tha >bit wa al-Mutah\}awwil: Bah\}th fi>al-Ittiba> 'wa al-Ibda> ' inda al-'Arab. Vol. II.

Adu>ni>s. al-Nas\}s\}\} al-Qur'a>ni> wa $A<f a>q$ al-Kita $>b a h$. Beirut: al-Da>r alAdab.

al-Khulli, Amin dan Nasr H $\{\mathrm{a}>$ mid Abu>Zayd. Metode Tafsir Sastra, terj. Khoiron Nahdliyin. Yogyakarta: Adab Press, 2004.

al-Ja>biri>, Muh \}ammad 'A<bid. Post Tradisionalisme Islam, terj. Ahmad Baso. Yogyakarta: LKIS, 2000.

al-Iskandari, Ahmad dan Mus \{t\} ofa 'Ana>ni. Al-Wasi>t\} fi> al-Adab al-'Arabi wa Tarikhihi. Kairo: Dar al-Ma'arif, 1978.

Braginsky, V.I. Yang Indah, Berfaedah Dan Kamal, Sejarah Sastra Melayu dalam Abad 7-19. terj. Hersri Setiawan. Jakarta: INIS, 1998.

Eagleton, Terry Marxisme and Literary Criticism, terj. Zaim Rafiqi. Depok: Desantara, 2002.

Fatawi, M. Faisol. Tafsir Sosiolinguistik Memahami Huruf Muqa>t\}a'ah dalam AlQur'an. Malang: UIN Malang Press, 2009.

Faisol, M. "Pengaruh Pemikiran Ibnu Madha' Tentang Ushul Al-Nahwi Al-'Arabi Dalam Memahami Teks Keagamaan,” Jurnal Lingua. www.jurnal.com.

Ismail, Prof. Dr. Faisal. Paradigma Pendidikan Islam, Analisis Historis, Kebijakan dan Keilmuan. PT remaja rosdakarya: 2017.

Mahayana, Maman S. Sembilan Jawabah Sastra Indonesia Sebuah Orientasi Kritik. Jakarta: Bening Publishing, 2005

Mastuki dan M. Ishom ElSaha (ed). Intelektual Pesantren, Potret Tokoh dan Cakrawala Pemikiran di Era pertumbuhan Pesantren. Jakarta: Diva Pu staka, 2003. 
Muzakki,Ahmad. Kesusastraan Arab Pengantar Teori dan Terapan. Yogyakarta: ArRuz Media, 2006.

Nyoman Kutha Ratna, Sastra dan Cultural Studies Representasi Fiksi dan Fakta (Yogyakarta: Pustaka Pelajar, 2010), 370.

Navis, A.A. Robohnya Surau Kami. Jakarta: PT Gramedia Pustaka Utama. 2004.

Shihab, M. Quraish. Membumikan Al-Qur'an Memfungsikan Wahyu dalam Kehidupan Jilid 2. Ciputat: Lentera Hati, 2011.

Shihab, M. Quraish. Tafsir al-Misbah Pesan, Kesan, dan Keserasian Al-Qur'an (Ciputat: Lentera Hati, 2011), 21.

Shihab, M. Quraish Pengetahuan Masyarakat Arab Jahiliyah Dalam Membaca Sirah Nabi Muhammad SAW dalam sorotan al-Qur'an dan Hadits-Hadits Shahih. Jakarta: Lentera Hati. 2011.

Tibi, Bassam. Islam, Kebudayaan dan Perubahan Sosial, terj. Misbah Zulfa Ellizabet, Zainul Abas Yogyakarta: PT Tiara Wacana Yogya, 1999.

Wargadinanta, Wildana dan Laily Fitriiani. Sastra Arab Dan Lintas Budaya. Malang: UIN Malang Press, 2008. 